\title{
ESQUEMA EVOLUTIVO DA SEDIMENTAÇÃO QUATERNÁRIA NAS FEIÇÕES DELTAICAS DOS RIOS SÃO FRANCISCO (SE/AL), JEQUITINHONHA (BA), DOCE (ES) E PARAÍBA DO SUL (RJ)
}

\author{
JOSÉ MARIA LANDIM DOMINGUEZ*, ABÍLIO CARLOS DA SILVA PINTO BITTENCOURT* \\ e LOUIS MARTIN**
}

\begin{abstract}
Quaternary sea level fluctuations along the east coast of Brazil played an important role on the development of the coastal plains of the São Francisco, Jequitinhonha, Doce e Paraíba do Sul rivers. The following eight stages have been recognized representing the Quaternary evolution of these features: Stage 1 - Pliocene - deposition of the Barreiras Formation as a series of alluvial fans; Stage 2 - Pleistocene - the Most Ancient Transgression; erosion during its course of the external front of the Barreiras Formation; Stage 3 Pleistocene - deposition at the foot of the coastal cliffs, carved in the Barreiras sediments by the Most Ancient Transgression; of coalescing alluvial fans; Stage $4-120,000$ years B.P. the Penultimate Transgression partially eroded the Pleistocene alluvial fans; Stage 5 - Drop of sea level, leading to the construction of coastal plains similar those which exist today; Stage $6-5,100$ years B.P. - - the Last Transgression partially eroded and drowned the Pleistocene coastal plains, which became in part isolated from the open sea by barrier islands; Stage 7 construction of intralagoonal deltas in the lagoon systems associated with the afore mentioned barrier-islands; and Stage 8 - a regression allowed the development of present day coastal plains.
\end{abstract}

INTRODUÇÃO Atualmente, quase todos os grandes rios que desaguam na costa brasileira apresentam, associada a suas desembocaduras, uma zona de progradação. Bacoccoli (1971), tomando por base a classificação de Fischer (1969), concluiu que essas zonas de progradação constituem deltas, assim identificando-os de norte para sul (Fig. 1): a) delta altamente destrutivo, dominado por marés - Rio Amazonas; $b$ ) deltas altamente destrutivos, dominados por ondas - rios Parnaiba, Jaguaribe, São Francisco, Jequitinhonha, Doce e Paraíba do Sul.

No presente trabalho serão discutidas apenas as feiçס̃es progradantes situadas na costa leste brasileira relacionadas aos rios São Francisco, Jequitinhonha, Doce e Paraíba do Sul, uma vez que os mesmos têm sido ultimamente objeto de uma série de estudos (Bandeira Jr. et al., 1975 e 1979; Bittencourt et al., no prelo; Dias, 1981; Dias e Gorini, 1980; Dominguez et al., no prelo; e Suguio et al., no prelo), cujos resultados já permitem sintetizar e estabelecer um modelo de evolução para essas feiçð̌es, durante o Quaternário, objetivo deste trabalho.

Os trabalhos de Bandeira Jr. et al. (1975 e 1979), Dias (1981) e Dias e Gorini (1980) - respectivamente, os dois primeiros, para o Rio Doce e, os dois últimos, para o Rio Paraíba do Sul - acompanham Bacoccoli (1971) no sen- tido de classificar como deltas as zonas progradantes nas desembocaduras desses rios, entêndendo que os mesmos são os principais responsáveis pelo aporte de sedimentos para o avanço da linha da costa. Por outro lado, Bittencourt et al. (no prelo), Dominguez et al. (no prelo) e Suguio et al. (no prelo) já pðrem em dúvida o papel desempenhado, respectivamente, pelos rios São Francisco, Jequitinhonha e Doce como principais supridores de terrigenos, entendendo que as zonas de progradação, construidas nas desembocaduras desses rios foram alimentadas principalmente pela deriva litorânea e pelas grandes quantidades de areia que iam sendo expostas na plataforma continental nos episódios regressivos quaternários que atingiram aquelas regiðes. Desse modo, no presente trabalho - e tendo em vista principalmente a inexistência, pelo que se conhece, de medidas conclusivas quanto à carga de fundo no baixo curso dos rios da costa leste brasileira, o que possibilitaria avaliar a efetiva contribuição dos mesmos como principais supridores de terrígenos para progradação - será evitado, de uma maneira geral, o uso do termo "delta" para designar essas feiçð̄es, preferindo-se a expressão feição deltaica, no sentido de um corpo sedimentar progradante, subaéreo, associado à desembocadura de um rio.

* Programa de Pesquisa e Pós-Graduação em Geofísica e Instituto de Geociências da UFBa, Rua Caetano Moura, 123, Federaçăo, CEP 40000 , Salvador, Bahia

** Office de la Recherche Scientifique et Technique Outre-Mer (ORSTOM), França, e Observatório Nacional, Rua General Bruce, 586, CEP 20000, Rio de Janeiro, RJ 


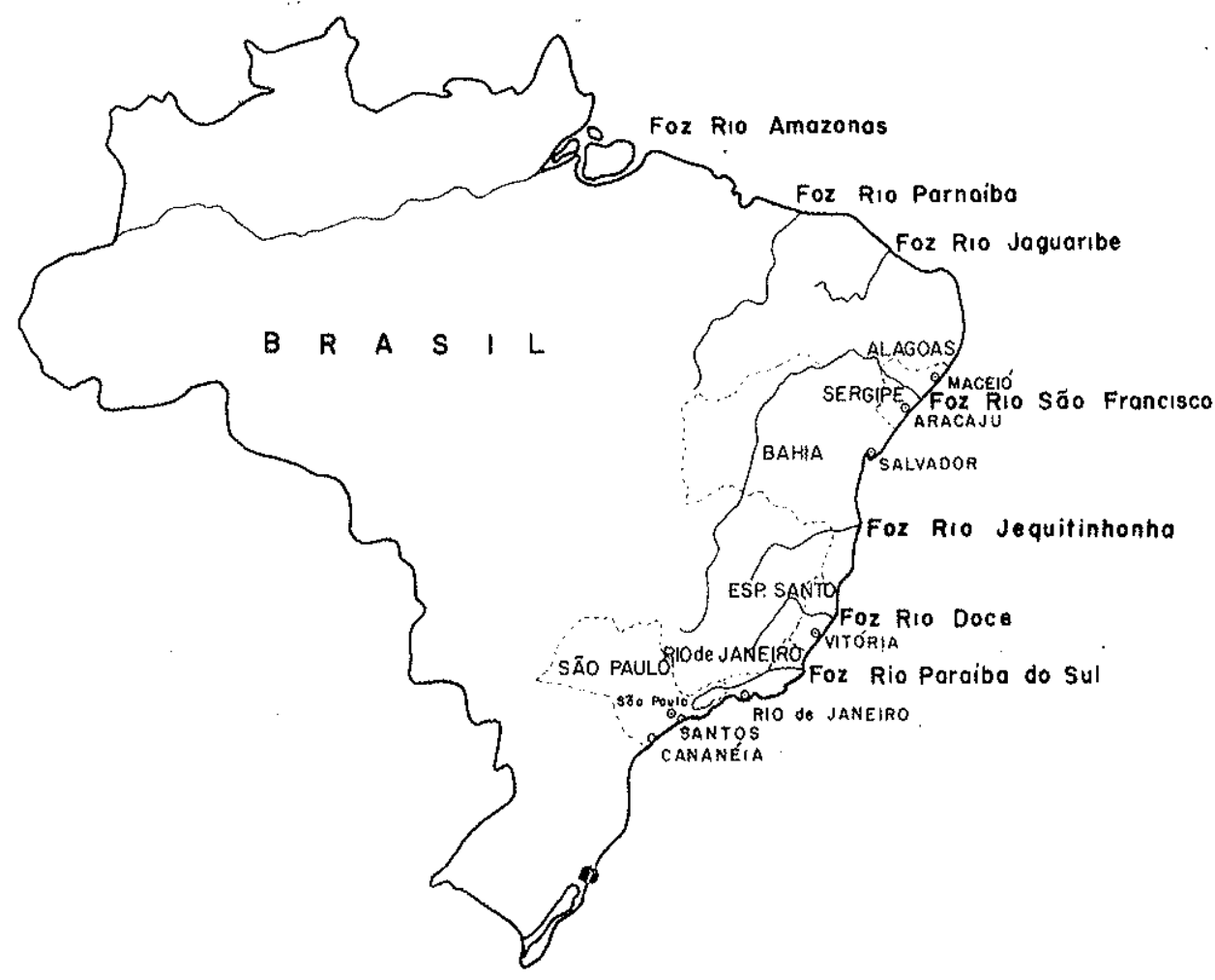

Figura I - Desembocaduras associadas a feições deltaicas da costa brasileira

TESTEMUNHOS DE ANTIGOS NIVEIS MARINHOS SITUADOS ACIMA DO NÍVEL ATUAL DO MAR AO LONGO DA COSTA LESTE BRASILEIRA Os trabalhos desenvolvidos por Bittencourt et al. (1979a e $b$, e em preparação) e Martin et al. (1979a e 1980a e $b$ ), para a região costeira dos Estados da Bahia e Sergipe, e por Suguio e Martin (1978), Suguio et al. (1980) e Martin et al. (1979b e 1980a), para a região costeira do Estado de São Paulo e a porção sul da costa do Estado do Rio de Janeiro, compreendendo uma extensão de cerca de $1840 \mathrm{~km}$ do litoral brasileiro, permitiram adquirir um conhecimento bastante satisfatório sobre as variações climáticas e do nivel relativo do mar, durante o Quaternário, para aquelas regiões. Esses autores, por meio de uma cartografia de detalhe e datações com $\mathrm{C}^{14}$, reconheceram dois conjuntos de terraços marinhos arenosos, testemunhos de dois importantes episódios transgressivos quaternários que afetaram aquelas regiōes. Respectivamente, o mais antigo e o mais recente, esses eventos foram chamados em São Paulo de transgressões Cananéia e Santos (Martin et al., 1979b) e, na Bahia, cujas denominações serão adotadas neste trabalho, de penúltima e última transgressões (Bittencourt et al., 1979a e $b$ ).

$\mathrm{Na}$ fase terminal da penúltima transgressão e na regressão subseqüente, foram depositados terraços arenosos cujo topo se situa em média de 6 a $10 \mathrm{~m}$ acima do nivel atual da preamar. Esses terraços apresentam na superfície coloração branca, que passa na base para marrom-escuro de natureza secundária, resultante da impregnação por ácidos húmicos e óxido de ferro, o que confere ao sedimento uma certa cimentação. A origem litorânea desses depósitos é atestada pela presença de tubos fósseis de Callianassa bem como pela presença sobre os terraços de vestígios de cristas de antigos cordões litorâneos, separadas por largas zonas intercordões. Amostras de coral coletadas numa formação recifal imediatamente abaixo de terraços com essas características, na localidade de Olivença (sul do Estado da Bahia), e datadas pelo método $\mathrm{Io} / \mathrm{U}$, forneceram idades situadas em torno de 120000 anos B.P. (Martin et al., no prelo), indicando portanto terem esses terraços sido depositados durante o Pleistoceno. Essa idade corresponde também, segundo aqueles autores, ao máximo alcançado pela penúltima transgressão.

Por volta de 17000 anos B.P., o nível do mar situavase aproximadamente a $110 \mathrm{~m}$ abaixo do nível atual (Bloom, 1977), portanto próximo à borda da plataforma continental. A partir daí começou a se caracterizar a última transgressão, holocênica, tendo o nivel do mar se elevado progressivamente até.culminar em um nivel relativo de cerca de $5 \mathrm{~m}$ acima do nível atual, por volta de 5 000-5 200 anos B.P. (Martin et al., 1980a). Durante a fase final desse evento e na regressão subseqüente, foram igualmente depositados terraços marinhos arenosos, cujo topo se situa de alguns centímetros até cerca de $4 \mathrm{~m}$ acima do nivel atual da preamar. A origem marinha e litorânea desses depósitos é atestada pela presença de conchas, de tubos fósseis de Callianassa, de estruturas sedimentares praiais e de alinhamentos de antigos cordðes litorâneos na superfície dos terraços. Esses cordões li- 
torâneos, estreitamente próximos e paralelos, de modo diferente dos encontrados nos terraços pleistocênicos, apresentam-se em notável estado de conservação (Bittencourt et al., 1979a). Datações com $\mathrm{C}^{14}$ de pedaços de madeira e conchas encontrados nesses terraços apresentam idades inferiores a 6000 anos B.P., indicando portanto terem os mesmos sido construídos durante o Holoceno. Essas datações, associadas às obtidas em outros testemunhos deixados pelo movimento regressivo geral subseqüente (incrustações de vermetídeos, corais etc.), permitiram reconstruir no tempo e no espaço antigas posições do nível do mar para diversos setores da região costeira compreendida pelos Estados da Bahia, Rio de Janeiro e São Paulo. Foram assim construídas, para essa região, curvas de variação relativa do nivel médio do mar durante aproximadamente os últimos 7000 anos (Martin et al., 1979a e 1980a; e Suguio et al., 1980) (Figs. I e 2). Essas curvas, de uma maneira geral, exibem grande similaridade de forma e mostram que o nível médio relativo do mar, durante o Holoceno, oscilou, passando por dois máximos e um mínimo na costa paulista e três máximos e dois mínimos na costa baiana. A não confirmação de um segundo mínimo e um terceiro máximo em São Paulo pode ser devido à ausência de bons testemunhos entre 3000 e 2500 anos B.P. (Martin et al., 1980a).

Cabe aqui mencionar que, embora não se conhecendo depósitos correlativos, Bittencourt et al. (1979a e $b$, no prelo e em preparação) reconheceram, para a costa dos Estados da Bahia e Sergipe, um terceiro evento transgres- sivo quaternário anterior aos outros dois aqui mencionados, e por eles denominado de transgressão mais antiga. Os únicos testemunhos desse episódio são representados por linhas de falésias mortas esculpidas nos sedimentos detríticos da Formação Barreiras. Nas regiões de Itacimirim (próximo a Salvador) e da metade sul da planície costeira associada à desembocadura do Rio São Francisco, essa linha de falésias é separada dos terraços marinhos pleistocênicos por um depósito continental, do tipo leques aluviais coalescentes, que foi retrabalhado parcialmente pelo mar durante a penúltima transgressão uma vez que os testemunhos por ela deixados repousam dire tamente sobre esses depósitos (Vilas Boas et al., 1979 e no prelo; e Bittencourt et al., no prelo e em preparação). Como apontam esses autores, esse fato evidencia que, efetivamente, aquelas falésias foram formadas durante um evento transgressivo anterior à penúltima transgressão. Bittencourt et al. (1979a) associaram esse episódio, no sul do Estado da Bahia, à deposição da Formação Caravelas (não aflorante). Esta formação, marinha rasa, calcária e rica em fósseis, foi datada em sua parte superior como sendo de idade pleistocênica (Carvalho e Garrido, 1966).

DEPÓSITOS QUATERNÁRIOS DAS FEIÇÕES DELTAICAS DOS RIOS SÃO FRANCISCO, JEQUITINHONHA, DOCE EPARAÍBA DO SUL Uma característica significativa das zonas de progradação associadas às desembocaduras dos rios São Francisco, Jequitinhonha, Doce e
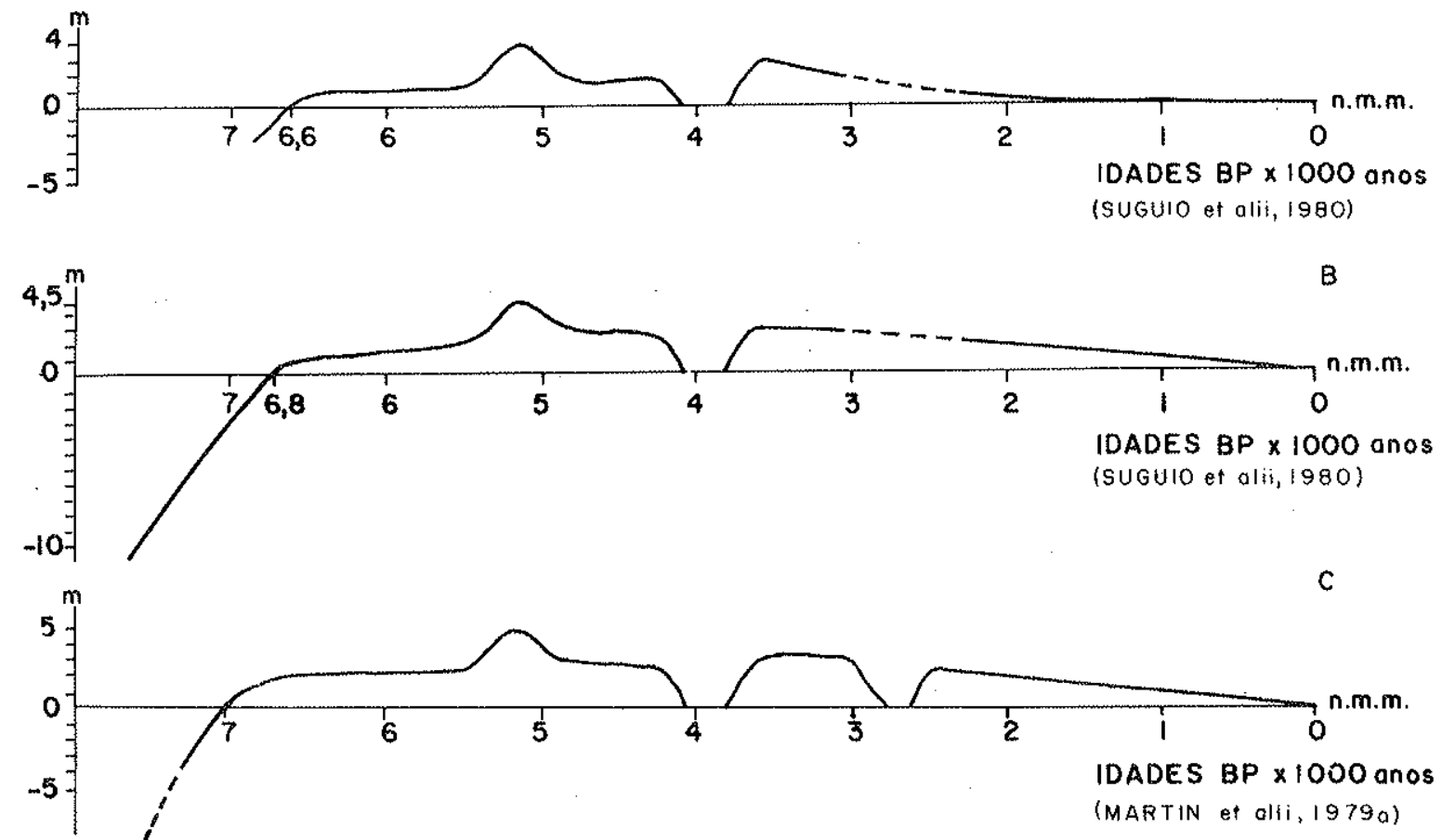

Figura 2 - Variaçōes relativas do nivel médio do mar durante os últimos 7.000 anos para as regióes de: $A-$ Cananéia (SP), $B-$ Samlos (SP), C - Salvador (BA) 
Paraiba do Sul (Fig. 3) é o fato de elas terem-se desenvolvido sempre em áreas de ocorrência da Formação Barreiras, que marca em terra, por meio de uma linha de falésia morta, o limite interior da planície costeira. Essas feiçőes deltaicas são constituídas, fundamentalmente, por depósitos associados a terraços marinhos, terraços fluviais, pântanos, mangues e lagunas. Nas planícles costeiras das desembocaduras dos rios Jequitinhonha e São Francisco, além desses, também são encontrados depósitos do tipo leques aluviais coalescentes bem como, ainda na foz do Rio São Francisco, importantes campos de dunas.

Terraços marinhos São os depósitos mais abundantes e que definem a conformação da feição deltaica, conferindo à mesma a forma cuspidata que a caracteriza. Nas feições deltaicas, respectivamente, dos rios São Francisco, Jequitinhonha e Doce, Bittencourt et al. (no prelo), Dominguez et al. (no prelo) e Suguio et al. (no prelo) reconheceram terraços marinhos associados à penúltima e à última transgressão, com as mesmas características aqui já descritas anteriormente. Quanto à feição deltaica do Rio Paraiba do Sul (Fig. 3), Dias e Gorini (1980) e Dias (1981) só identificam terraços marinhos relacionados à última transgressão. Contudo, ao se observar em fotos aéreas o aspecto geomórfico dos feixes de cordðes litorâneos que aparecem na região de Caboios, sudoeste de São Tomé e a nordeste de Campos, constata-se que os mesmos apresentam características idênticas aos dos relacionados aos terraços da penúltima transgressão mencionados no item anterior. Ademais, observaçð̌es de campo feitas por um dos autores (J. M. L. Dominguez) conduzem ao mesmo tipo de raciocínio. O fato de esses cordőes arenosos na região a sudoeste de Săo Tomé se situarem praticamente no mesmo nível altimétrico dos atribuídos à última transgressão (Dias e Gorin, 1980; e Dias, 1981) poderia ser explicado por movimentos de subsidência locais posteriores a 120000 anos B.P. Sabe-se, por exemplo, que a bacia sedimentar de Campos, onde está situada a zona progradante do Rio Paraíba do Sul, foi afetada por reativamento tectônico durante o Terciário (Schaller, 1973), cujos efeitos provavelmente podem ter continuado sensíveis durante o Quaternário. Desse modo, nos locais anteriormente mencionados, os terraços arenosos são aqui mapeados como associados à penúltima transgressão (Fig. 3).

Terraços fluviais São constituídos basicamente de sedimentos de dique marginal, barra de meandro e canal abandonado. Esses terraços colocam-se em discordância erosiva sobre os terraços marinhos, o que é bem exemplificado nas feições deltaicas dos rios São Francisco e Jequitinhonha (Fig.3). Nas zonas progradantes dos rios Doce e Paraiba do Sul, os terraços fluviais estão restritos aos deltas intralagunares construídos por esses dois rios durante uma importante etapa de sua evolução (Fig. 3), conforme será discutido adiante.

Mangues Nas desembocaduras abandonadas pelos rios e seus distributários ou nas regioes protegidas pela presença de ilhas arenosas, o clima quente e úmido que atualmente predomina na costa leste brasileira favoreceu a instalação de manguezais. Essa situação é muito bem ilustrada na metade norte da feição deltaica do Rio Jequitinhonha e nas vizinhanças das desembocaduras dos rios São Francisco e Paraíba do Sul (Fig. 3).

Sedimentos lagunares Separando os terraços marinhos holocênicos dos pleistocênicos, são encontradas zonas baixas preenchidas por sedimentos argilosos de cor cinza a preta, ricos em conchas marinhas e lagunares $\left(O_{S-}\right.$ trea, Anomalocardia, Lucina), e matéria orgânica. Conforme será discutido em seguida, esses sedimentos foram depositados em antigas lagunas que se formaram naquelas regiões por volta da última transgressão e alcançam maior expressividade nas feições deltaicas dos rios Doce e Paraíba do Sul (Fig. 3).

Pântanos Esses ambientes substituíram as lagunas que secaram quando do evento regressivo que se seguiu à última transgressão. Esses depósitos, onde predominam atualmente acumulações de turfas, ocupam também as zonas baixas alagadiças intercordðes bem como as regiōes adjacentes aos diques marginais dos rios, onde constituem os depósitos de várzea.

Leques aluviais coalescentes Esses depósitos são sempre encontrados no sopé das encostas da Formação Barreiras, com altitudes variando de 10 a $20 \mathrm{~m}$. Apresentam-se sempre não consolidados e com coloração esbranquiçada, sendo predominantemente arenosos e mal selecionados, contendo de argila a seixos.

Dunas Dispondo-se ao longo de quase toda parte externa da feição deltaica do Rio São Francisco, são encontradas duas geraçōes de dunas (Fig. 3): uma mais interna, subatual e já povoada pela vegetação, e uma externa, de dunas em franco desenvolvimento, que cobre em parte a primeira. Essas dunas podem atingir altitudes de até $30 \mathrm{~m}$.

\section{ESQUEMA EVOLUTIVO DA SEDIMENTACCÃO QUA-} TERNÁRIA NAS FEIÇÕES DELTAICAS DOS RIOS SÃO FRANCISCO, JEQUITINHONHA, DOCE E PARAÍBA DO SUL A aplicação dos conhecimentos já adquiridos sobre a evolução da costa brasileira durante o Quaternário, associada a datações absolutas com $C^{14}$ de amostras coletadas nos diversos subambientes das feiçðes deltaicas aqui analisadas, permitiu traçar um quadro evolutivo para essas feiçóes durante o Quaternário. De uma maneira geral, foi possível reconhecer oito estágios principais na história do desenvolvimento das feições deltaicas estudadas, embora os mesmos nem sempre estejam bem representados.

Estágio I (Fig. 4A) Corresponde à deposição da Formação Barreiras, durante o Plioceno. Nessa época, um clima mais seco que o atual, sujeito a tempestades esporádicas e violentas, deu lugar à deposição de leques aluviais coalescentes no sopé das encostas, que constituem os depósitos daquela formação (Vilas Boas et al. 1979 e no prelo). Durante a deposição dessa formação, o nível relativo do mar encontrava-se mais baixo que o atual, tendo seus sedimentos recoberto parte da plataforma continental (Bigarella e Andrade, 1965). 


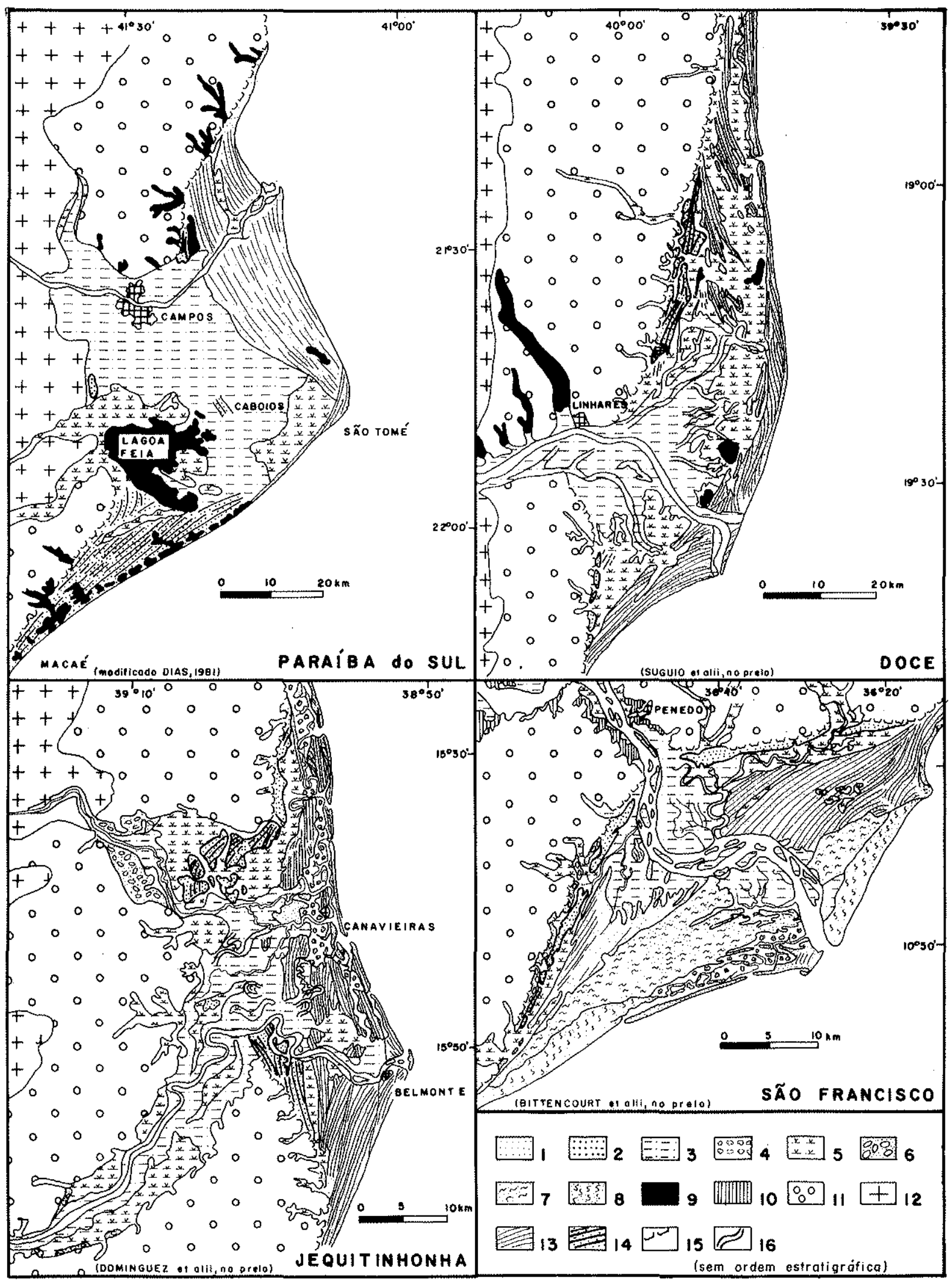

Figura 3 - Mapas geológicos das feições deltaicas da costa leste brasileira: 1 - terraço marinho holocênico; 2 - terraço marinho pleistocênico; 3 - terraço fluvial; 4 - mangue; 5 - pântano; 6 - leques aluviais pleistocênicos; 7 - dunas fixadas; 8 - dunas ativas; 9 - lagoas; 10 - sedimentos da bacia Sergipe-Alagoas; 11 - Formação Barreiras; 12 - embasamento pré-cambriano; 13 - alinhamentos cordôes litorâneos holocênicos; 14 - alinhamentos cordôes litoraneos pleistocênicos; 15 - falésia morta; 16 - canal abandonado. Esta legenda também é válida para as Figs. 5 e 6. 
Estágio II (Fig. 4B) A deposição da Formação Barreiras foi interrompida quando o clima passou a adquirir características úmidas (Vilas Boas $e t$ al., 1979). Esse tempo coincide com o início do episódio transgressivo mencionado por Bittencourt et al. (1979a) como a transgressão mais antiga. Esse episódio erodiu a porção externa da Formação Barreiras, sendo o limite máximo atingido pelo mar representado por antigas linhas de falésias entalhadas nessa formação. Na região da feição deltaica do Rio São Francisco, inclusive, esse evento transgressivo teve sua ação erosiva favorecida pelo reativamento de antigas falhas do embasamento cristalino (Bittencourt et al., no prelo).

Ainda que Suguio et al. (no prelo), Dias e Gorini (1980), e Dias (1981) não mencionem esse evento para as planícies costeiras dos rios Doce e Paraíba do Sul, é provável que a transgressão mais antiga tenha também afetado essas regið̌es uma vez que, como foi visto, a costa leste brasileira parece ter-se comportado de maneira bastante homogênea no que diz respeito às variaçðes relativas do nível do mar durante o Quaternário. Conforme foi mencionado anteriormente, a falésia original representativa desse estágio encontra-se preservada apenas na metade sul da planície costeira do Rio São Francisco (Fig. 3 ); nas dẹmais regiões, as falésias esculpidas pela transgressão mais antiga foram retrabalhadas durante a penúltima transgressão.

Estágio III (Fig. 4C) Após o máximo alcançado pela transgressão mais antiga, e durante a regressão que se seguiu, o clima voltou a adquirir características semi-áridas, pelo menos para as regioes das planícies costeiras dos rios São Francisco e Jequitinhonha. Essa retomada de condiçðes climáticas semelhantes às prevalecentes durante a deposição da Formação Barreiras propiciou a formação de novos depósitos continentais do tipo leques aluviais coalescentes no sopé das falésias esculpidas na Barreiras durante o evento transgressivo anterior. Tal situação se estendeu por toda a costa dos Estados da Bahia e Sergipe, como apontam os trabalhos de Vilas Boas et al. (1979 e no prelo), Martin et al. (1980b) e Bittencourt et al. (em preparação).

Estágio IV (Fig. 4D) Corresponde ao máximo alcançado pela penúltima transgressão (120000 anos B.P.). Nessa época, o nível do mar erodiu total ou parcialmente os depósitos continentais colocados durante o estágio anterior. Durante esse evento, os baixos cursos dos rios São Francisco, Jequitinhonha, Doce e Paraíba do Sul foram afogados constituindo estuários. Nessa ocasião, nos locais em que o mar conseguiu erodir totalmente os sedimentos continentais depositados no estágio anterior, as ondas retrabalharam a linha de falésias construída na Formação Barreiras durante a transgressão mais antiga.

Estágio V (Fig. 4E) Esse estágio corresponde ao evento regressivo subsequiente à transgressão anterior. Nessa época, foram construídos então os terraços marinhos pleistocênicos, que possivelmente formaram planícies costeiras semelhantes às atuais.

Estágio VI (Fig. 4F) A última transgressão erodiu e afogou parcialmente, durante seu curso, as planicies as- sociadas aos rios aqui considerados. A rede de drenagem que se havia instalado nos terraços pleistocênicos, favorecida pela descida acentuada do nível de base que caracterizou o evento anterior, foi invadida pelo mar da mesma maneira que o foram alguns valores escavados na Formação Barreiras. Durante o máximo dessa transgressão, os baixos cursos dos rios São Francisco, Jequitinhonha, Doce e Paraíba do Sul foram mais uma vez parcialmente afogados, constituindo estuários.

Associado ao afogamento da planície costeira pleistocênica, iniciou-se o desenvolvimento de ilhas-barreiras, que isolaram de um contato direto com o mar o que restou dos terraços marinhos relacionados àquelas planícies. Atrás dessas ilhas instalaram-se sistemas lagunares que em algumas regiőes alcançaram dimensð̃es consideráveis, a exemplo das planícies costeiras dos rios Doce (Suguio et al., no prelo) e Paraíba do Sul (observação dos autores). Datações com $\mathrm{C}^{14}$ de conchas e pedaços de madeira coletados nos sedimentos lagunares das planícies costeiras dos rios São Francisco (A.C.S.P. Bittencourt, comunicação oral), Jequitinhonha (Dominguez et al., no prelo), Doce (Suguio et al., no prelo) e Paraíba do Sul (G.T.M. Dias, comunicação oral) forneceram idades em torno de 6000 anos B.P., indicando portanto que as ilhas-barreiras já se haviam instalado antes de ser alcançado o máximo da última transgressão.

As Figs. $5 A$ e $6 A$ mostram, respectivamente, a reconstituição paleogeográfica das planícies costeiras dos rios Jequitinhonha e Doce durante esse estágio.

-Estágio VII (Fig. 4G) Nas lagunas instaladas no estágio anterior foram construídos deltas intralagunares pelos rios que nela penetravam. Este estágio encontra-se bem representado nas planícies costeiras dos rios Doce e Paraíba do Sul. Essas feições constituem de fato as únicas acumulações sedimentares presentes nas planícies costeiras aqui analisadas, que podem ser consideradas como deltas típicos, uma vez que foram construídas a partir dos aportes sedimentares fluviais aprisionados nessas lagunas, exibindo uma morfologia característica dos deltas de domínio fluvial.

Na planície costeira do Rio Paraíba do Sul, o delta intralagunar seria representada pelo que Dias (1981) denomina complexo fluvial Campos-São Tomé. Lamego (1955) reconheceu nessa feição um antigo delta do tipo Mississípi. É evidente que um delta desse tipo não se poderia desenvolver em condições de mar aberto devido à elevada energia de onda que predomina no litoral campista. Dias e Gorini (1980), e Dias (1981) reconhecem esse fato mas não esclarecem perfeitamente a natureza daquela feição. Acreditam esses autores que a mesma representa um delta "dominado por marés", segundo a classificação de Galloway (1975), e que foi preservado da ação erosiva das ondas de alta energia pela existência de ilhasbarreiras. É difícil, entretanto, aceitar que o complexo fluvial Campos-São Tomé represente um delta "dominado por marés" tendo em vista que a amplitude das marés para a região é inferior a $2 \mathrm{~m}(D H N, 1981)$, enquanto feições desse tipo se desenvolvem de preferência em ambientes de macromaré ( $>4 \mathrm{~m}$ ). Desse modo, é mais simples atribuir para esse complexo fluvial a categoria de delta intralagunar, semelhante ao observado por Suguio et al. (no prelo) na planície costeira do Rio Doce. De 

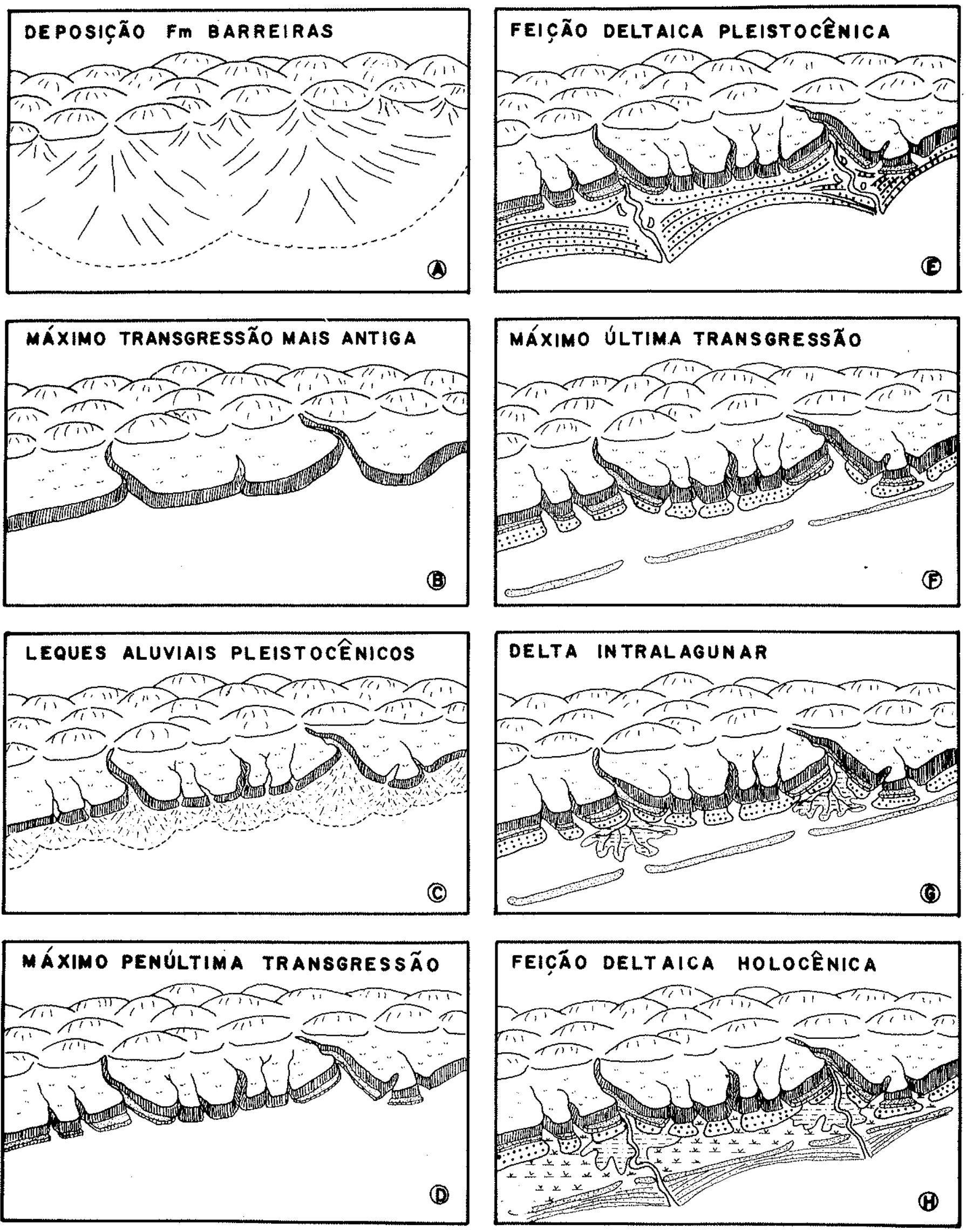

Figura 4 - Esquema evolutivo da sedimentação quaternária nas feiçoes deltaicas da costa leste brasileira 

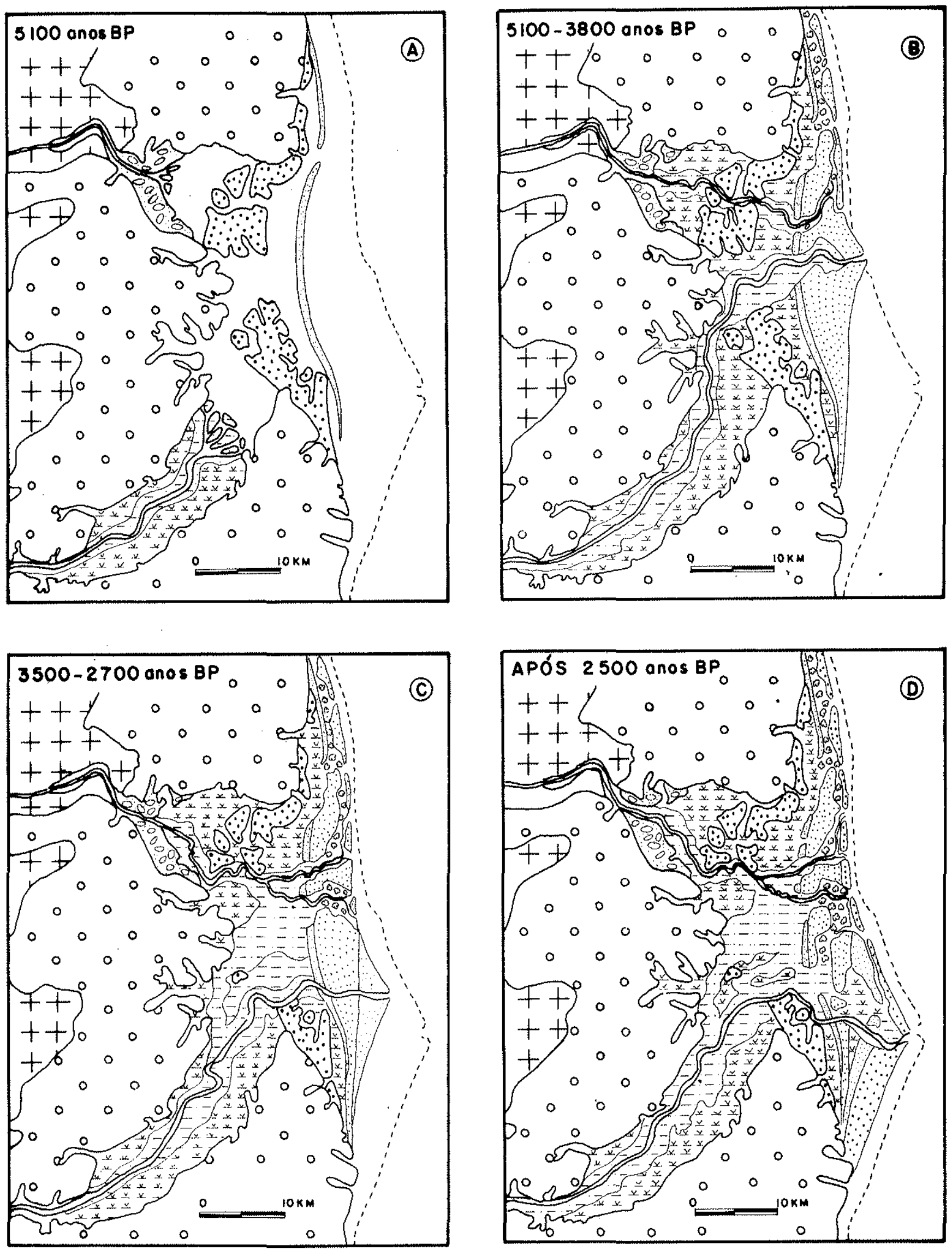

Figura 5 - Evolução paleogeográfica da feição deltaica do Rio Jequitinhonha durante o Holoceno (segundo Dominguez et al., no prelo). A linha tracejada indica a posição da linha da costa atual (ver a legenda Fig. 3) 

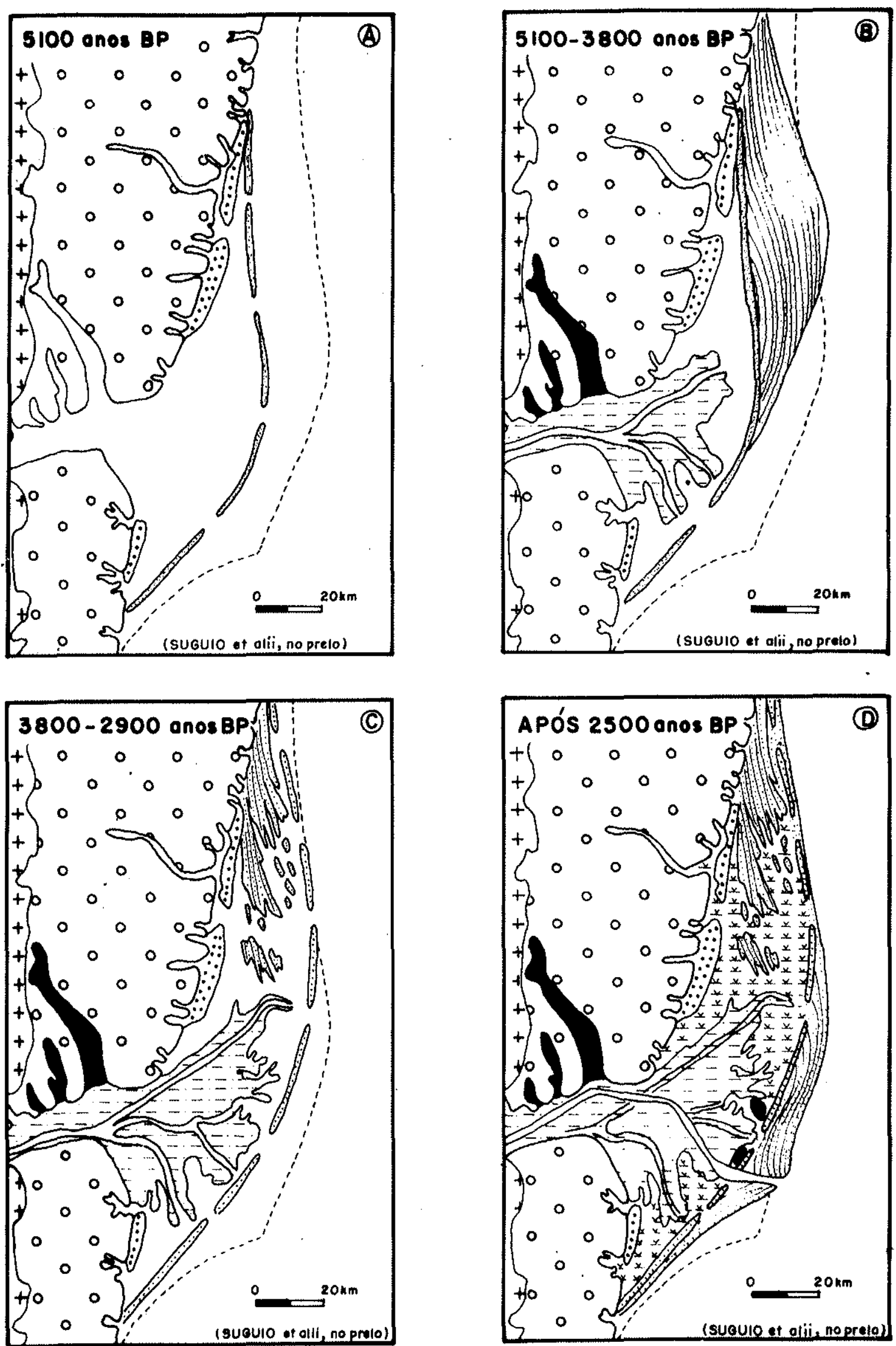

Figura 6 - Evolução paleogeográfica da feição deltaica do Rio Doce durante o Holoceno (modificado de Suguio et al., no prelo). A linha tracejada indica a posição da linha da costa atual (ver legenda da Fig. 3) 
fato, tanto o delta intralagunar quanto o complexo fluvial Campos-São Tomé apresentam as características típicas dos deltas construídos dentro de um corpo de água rasa, com baixos níveis de energia (uma laguna), nos quais, como observa Wright (1977), o predomínio de forças friccionais resulta um elevado número de bifurcaçoes para as construçð̃es resultantes. No Rio Doce, o delta intram lagunar apresenta um grau extraordinário de conservação, sendo possivel reconstituir perfeitamente seu aspecto morfológico original (Figs. $6 C$ e $D$ ).

Nas planícies costeiras dos rios São Francisco e Jequitinhonha, este estágio não está bem representado, provavelmente devido ao fato de que as lagunas que ai se instalaram apresentavam dimensóes bastante reduzidas, tendo sido rapidamente colmatadas e atravessadas por esses rios na busca de um caminho para o mar.

Estágio VIII(Fig. 4H) O abaixamento do nível relativo do mar, que se seguiu ao máximo transgressivo de 5100 anos B.P. (Martin et al., 1980a), traduziu-se na formação de terraços marinhos, a partir da ilha-barreira original, o que resultou na progradação da linha da costa. Para a planície costeira do Rio Doce, Suguio et al. (no prelo) mencionam a formação de uma primeira geração de cordóes holocênicos entre 5100 e 3800 anos B.P. (Fig. $6 B$ ). E interessante notar que durante a construção da primeira geração de cordões o Rio Doce ainda não alcançava diretamente o mar, ficando toda sua carga sedimentar retida na laguna, sendo utilizada para a construção do delta intralagunar (Suguio et al., no prelo) (Fig. 6B).

Durante essa fase regressiva, Dominguez et al. (no prelo) se referem à formação de uma primeira feição deltaica holocênica para a planície costeira do Rio Jequitinhonha (Fig. $5 B$ ) e Bittencourt et $a l$. (no prelo), à construção de uma segunda geração de cordóes arenosos (a primeira de idade pleistocênica) para a do Rio São Francisco.

Nesse estágio, além da construção dos terraços marinhos arenosos, o abaixamento do nível relativo do mar provocou também o desaparecimento dos sistemas lagunares, que fo- ram. substituídos por zonas baixas pantanosas. Restos dessas antigas lagunas são representados nos dias atuais por diversas lagoas presentes na planície costeira do Rio Doce (Suguio et al., no prelo) e provavelmente pela Lagoa Feia para a planície costeira do Rio Paraíba do Sul.

Os pequenos e relativamente rápidos episódios transgressivos holocênicos, que aparecem representados nas curvas de variações relativas do nível do mar de Suguio et al. (1980) e Martin et al. (1979a), exerceram um importante papel no desenvolvimento das planícies costeiras aqui consideradas. Para a planície costeira do Rio Doce, Suguio et al. (no prelo) registram uma segunda fase lagunar associada ao evento transgressivo de $3800-3600$ anos B.P. (Fig. 2), com formação de novas ilhas-barreiras e afogamento da primeira geração de terraços holocênicos (Fig. 6C). Na planície costeira do Rio Jequitinhonha, esses eventos transgressivos rápidos traduziram-se no afogamento das desembocaduras dos rios associado à mudança do curso fluvial por um processo de avulsão. Nas novas desembocaduras ocupadas foram construídas nos eventos regressivos seguintes novas feiçðes deltaicas (Dominguez et al., no prelo). Assim, por exemplo, durante o evento transgressivo de $3800-3600$ anos B.P. (Fig. 2C), a primeira feição deltaica holocênica do Rio Jequitinhonha foi afogada e o curso fluvial se deslocou mais para o sul. Na nova desembocadura ocupada foi construída, no evento regressivo situado entre 3500 e 2700 anos B.P., a segunda feição deltaica holocênica desse rio (Fig. 5C). Essa zona de progradação foi afogada durante o episódio transgressivo de 2 700-2 500 anos B.P. (Fig. 2C), que forçou também uma mudança no curso do rio para a posição que ocupa atualmente. $\mathrm{Na}$ regressão que se seguiu após 2500 anos B. P. foi construída, desde aquela data até o tempo atual, a terceira e atual feição deltaica do Rio Jequitinhonha (Fig. $5 D$ ).

Nas planícies costeiras dos rios São Francisco e Paraíba do Sul não se sabe ainda qual o papel desempenhado por esses rápidos episódios transgressivos holocêni$\cos$, devido principalmente à carência de datações e à necessidade de estudos mais detalhados.

\section{BIBLIOGRAFIA}

BACOCCOL.l, G. - 1971 - Os deltas marinhos holocênicos brasileiros: uma tentativa de classificação. Bol: Técn. Petrobrás 14:5-38.

BANDEIRA Jr., A.N., PETRI, S. e SUGUIO, K. - 1975 - Projeto Rio Doce (relatório final), CENPES/Petrobrás, $203 \mathrm{pp}$.

BANDEIRA Jr., A.N., PETRI, S. e SUGUIO, K. - 1979 - The Doce river delta: an example of a highly destructive wave-dominated quaternary dekta on the brazilian at\}antic coastline, State of Espírito Santo. In: K. Suguio, R.R. Fairchild, L. Martin e J.M. Flexor (eds.), Proceedings of the 1978 International Symposium on Coastal Evolution in the Quaternary, Sao Paulo: 275-295

BIGARELLA, J.J. e ANDRADE, G.O. de - 1964 - Consideraçðes sobre a es tratigrafia dos sedimentos cenozóicos em Pernambuco (Grupo Barreiras). Univ. Recife, Arq. Inst. Ciên. Terra 2:2-14.

BITIENCOURT, A.C.S.P., MARTIN, L., VILAS BOAS., G.S. E FLEXOR, J.M. - 1979a - Quaternary marine formations of the coast of the State of Bailia (Brazil), In: K. Sugutio, R.R. Fairchild; L. Martin e J.M. Flexor (eds.), Proceedings of the 5978 International Symposium on Coastal Evolution in the Quaternary, Săo Paulo: 232-253.

BITTENCOURT, A.C.S.P., VILAS BOAS, G.S., FLEXOR, J.M. e MARTIN, L. - $1979 b$ - Geologia dos depósitos quaternários no litoral do Estado da Bahia. In: H. Inda (ed.), Geologia e Recursos Minerais do Estado da Bahia, Texios Básicos, SME/CPM, Salvador (BA): 1-21.

BITTENCOURT, A.C.S.P., DOMINGUEZ, J.M.L., MARTIN, L. C FERREIRA, Y.A. - no prelo -- Dados prelininares sobre a cvoluça do delta do rio Sảo Francisco (SE-AL) durante o Quaternário: influência das variaçőes do nivel do mar, Anais do IV Simposio do Quaternário no Brasil (C'TCQ/SBG), Rio de Janeiro.
BITTENCOURT, A.C.S.P., MARTIN, L., DOMINGUEZ, J.M.L. E FERREIRA, Y,A. - em preparação - Geologia do Quaternário Costeiro do Estado de Sergipe.

BLOOM, A.L. - 1977 - Atlas of Sea Level Changes, 1.G.C.P. Project, 61, 121 $\mathrm{pp}$.

CARVALHO, K.W.B. e GARRIDO, J.L.P. - 1966 - Reconhecimento geológico da Bacia sedimentar Bahia Sul/Espírito Santo, Petrobrás/Dexpro, Rel. 2496 .

DHN - 1981 - Tábuas das marés para o ano de 198i, Costa do Brasil e portos estrangeiros, $217 \mathrm{pp}$.

DIAS, G.T.M. e GORINI, M.A. - 1980 - A Baixada Campista: estudo morfológico dos ambientes litorâneos. Anais do XXXI Congresso Brasileiro de Geologia, Camboriú (SC), 1:588-602.

DIAS, G.T.M. - 1981 - O Complexo Deltaico do rio Paralba. IV Simpósio do Quaternário no Brasil (CTCQ/SBG), Publ. Esp. n. 2: 58-79, Rio de Janeiro.

DOMINGUEZ, J.M.L., MARTIN, L. e BITTENCOURT, A.C.S.P. - no prelo - Evolução palcogeográfica do delta do rio Jequitinhonba (BA) durante o Quaternário: influência das variações do nivel do mar. Anais do IV Simpósio do Quaternário no Brasil (CTCQ/SBG), Rio de Janeiro.

FISCHER, W.L. - 1969 - Facies characterization of gulf coast Basin Delta systems, with some Holocene analogues. Transactions of G.C.A.G.S., 19.

GALLOWAY, W.E. - 1975 - Process framework for describing the morphologic and stratigraphic evolution of deltaic depositional systems. In: M.L. Broussard (ed.), Deltas, Models for Exploration. Houston Geological Society, EUA: 87.98 . 
LAMEGO, A.R - 1955 - Geologia das quadrículas de Campos, São Tomé, La goa Feia e Xexéu. Div. Geol. Min., DNPM, Bol. 154. Rio de Janeiro, $60 \mathrm{pp}$. MARTIN, L., FLEXOR, J.M., VILAS BOAS, G.S., BITTENCOURT, A.C.S.P. e GUIMARÃES, M.M.M., - $1979 a-$ Courbe de variations du niveau retatif de fa mer au cours des 7.000 dernières années sur un secteur homogène du littoral brésilien (Nord de Salvador-Bahia), In: K. Suguio, R.R. Fairchild, L. Martin e J.M. Flexor (eds.), Proceedings of the 1978 International Symposium on Coastal Evolution in the Quaternary, São Paulo: 264-274

MARTIN, L., SUGUIO, K. e GLEXOR, J.M. - 1979b - Le Quaternaire marin entre Cananéia (Sżo Paulo) et Barra de Guaratiba (Rio de Janeiro). In: K. Suguio, R.R. Fairchild, L. Martin e J.M. Flexor (eds.), Proceedings of the 1978 International Symposium on Coastal Evolution in the Quaternary, Så Paulo: 296-331

MARTIN, L., SUGUIO, K., FLEXOR, J.M, BITrENCOURT, A.C.S.P. e VILAS BOAS, G.S - $1980 a$ - Le Quaternaire marin brésilien (Littoral Paulista, Sứ Fluminense et Bahianais). Cah. O.R.S.T.O.M. Série Géologie, XI: 95. 124.

MARTIN, L., BITTENCOURT, A.C.S.P., VILAS BOAS, G.S. E FLEXOR, J.M. - $1980 b$ - Texto explicativo para o mapa geológico do Quaternário costciro do Estado da Bahia - Escala 1:250.000. CPM, SME, Salvador (BA), $60 \mathrm{pp}$.

MARTIN, L., BITTENCOURT, A.C.S.P. e VILAS BOAS, G.S. - no prelo Primejra ocorrência de corais pleistocênicos na costa brasileira - Datação do máximo da Penúltima Transgressåo, Rev. Ciências da Terra.

SCHALLER, H. - 1973 - Estratigrafia da Bacia de Campos. Anais do XXVII Congresso Brasileiro de Geologia 3: 247-258, Aracaju (SE).
SUGUIO, K. e MARTIN, L. - 1978 - Quaternary marine formations of the State of São Paulo and Southern Rio de Janeiro. Special Publication n: 1, 1978 international Symposium on Coastal Evolution in the Quaternary, 55 pp.

SUGUIO, K., MARTIN, L. e FLEXOR, J.M. - 1980 - Sea-level fluctuations during the past 6,000 years along the coast of the State of São Paulo, Brazil. In: N.A. Morner (ed.), Earth Rheology, Isostasy and Eustasy, John Willey and Sons: $471-486$.

SUGUIO, K., MARTIN, L. e DOMINGUEZ, J.M.L. - no prelo - Evoluçăo da planicie costeira do rio Doce (ES) durante o Quaternário: influência das variaçð̃es do nivel do mar. Anais do IV Simpósio do Quaternário no Brasil (CTCQ/SBG), Rio de Janeiro.

VILAS BOAS, G.S., MARTIN, L., BITTENCOURT, A.C.S.P. E FLEXOR, J.M. - 1979 - Paleogeographic and paleoclimatic evolution during the Quaternary in the Northern hals of the coast of the State of Bahia, Brazil. In: K. Suguio, R.R. Fairchild, L. Martin e J.M. Flexor (eds.), Proceedings of the 1978 International Symposium on Coastal Evolution in the Quaternary, Såo Paulo: 254-263.

VILAS BOAS, G.S., BITTENCOURT, A.C.S.P. e MARTIN, L. - no prelo Leques aluviais pleistocênicos da regiåo costeira do Estado da Bahia - Con. seqtências Paleoclimáticas. Rev. Bras. Geociéncias.

WRIGHT, L.D. - 1977 - Sediment transport and deposition at river mouths: a synthesis. Geol. Soc. Amer. Bull. 88: 857-868. 